\title{
Cognitive Profile of Paranoid Schizophrenia on LNNB
}

\author{
Susmita Halder ${ }^{1}$, Akash Kumar Mahato ${ }^{2}$, Masroor Jahan ${ }^{3}$
}

\section{ABSTRACT:}

Schizophrenia is a major psychiatric disorder characterized by a disruption in affective, cognitive and social domains, which results in compromised ability to adapt to a changing environment and to function adequately in the community.

Schizophrenia is often accompanied by gross and progressive impairment in different functional areas of a person. They are mostly seen in the form of - cognitive impairment (executive functions, information processing, attention, learning and memory), psychomotor activity, speech, thought process, perception, and abstraction. These deficits are evident in nearly all individuals diagnosed with schizophrenia, and their impact on the employment, social relationships and living status of patients is devastating. However, there could be differences among cognitive profiles of different schizophrenia subtypes.

Luria Nebraska Neuropsychological Battery (LNNB) is a widely used standardized neuropsychological tool for cognitive assessment. In the present study, 30 male paranoid schizophrenia patients were assessed on the LNNB- Form I to see the profile of cognitive functioning on this tool.

Keywords: LNNB, cognitive deficit, Paranoid schizophrenia.

Cognitive impairment is gradually been considered as a core feature of schizophrenia. Extensive research has suggested that the cognitive deficits frequently associated with schizophrenia are not merely a consequence of psychotic symptoms or its treatment, but rather a distinct dimension of the illness. Perhaps one of the most challenging aspects of treating patients with schizophrenia is coping with the severe cognitive deficits that accompany the disease. In psychiatric disorders like schizophrenia the search for structural abnormalities of the brain has been one of the main approaches to study the organic basis of illness. The majority of earlier neuropsychological investigations of schizophrenics were concerned with differentiating them from brain damaged neurological patients, based on the assumption that they are functional disorder (Heaton, et al., 1978).

${ }^{1}$ Assistant Professor in Clinical Psychology, Amity University, Rajasthan.

${ }^{2}$ Assistant Professor in Clinical Psychology, Amity University, Rajasthan.

${ }^{3}$ Additional Professor in Clinical Psychology. RINPAS, Ranchi

(C) 2015 I S Halder, A Mahato, M Jahan; licensee IJIP. This is an Open Access Research distributed under the terms of the Creative Commons Attribution License (http://creativecommons.org/licenses/by/2.0), which permits unrestricted use, distribution, and reproduction in any Medium, provided the original work is properly cited. 


\section{Cognitive Profile of Paranoid Schizophrenia on LNNB}

Recent studies have followed the trend of comparing subgroups of schizophrenia itself instead of comparing schizophrenia with other disorders. Findings suggested that several subgroups of schizophrenia have different levels of cognitive deficits, and some of them show signs of brain dysfunction. Several research studies have reported more cognitive impairment in chronic/ process/ non paranoid schizophrenia in comparisons to acute/ reactive/ paranoid schizophrenia (Robertson \& Taylor, 1985; Langell et al., 1987).

The distinctiveness of a paranoid subtype can be traced back to the early work of Bleuler and Kraepelin, through psychodynamic theorists, to more modern investigations (Magaro 1981). Tsuang and Winokur (1974) suggested that a smaller percentage of patients with paranoid subtype had psychomotor symptoms than hebephrenic patients. Paranoid patients were characterized by later onset of illness, less seclusiveness, less distractibility, fewer psychomotor symptoms, a higher incidence of marriage, more children, and less disruption of social and familial relationships. Others have differentiated between positive and negative syndromes, suggesting that deficit symptoms are associated with abnormal brain morphology (Andreasen and Olsen 1982). Alternative sub- classifications of schizophrenia (e.g., process vs. reactive, late vs. early onset, acute vs. chronic course of illness) may also intersect with the paranoid/nonparanoid distinction.

Discussions of cognitive differences, such as attention deficits, among subtypes have appeared in global reviews of neuropsychological correlates of schizophrenia (Levin et al. 1989), leading researchers to suggest that each subgroup of schizophrenia has a unique pattern of neuropsychological impairment. In fact, there is wide clinical acceptance that paranoid schizophrenia patients display less regression of mental faculties than their non-paranoid counterparts. Seidman's (1983) comprehensive review of neurophysiological and neuropsychological findings, as well as Magaro's (1981) review of information processing in schizophrenia, suggests meaningful distinctions in cognitive functioning among schizophrenia subtypes.

Identification of subtype-specific cognitive profiles may help refine theories concerning multiple causal pathways in schizophrenia. The LNNB is a comprehensive tool to assess neuropsychological functions. The performance on LNNB has been reported to be positively correlated with CT scan, and regional cerebral blood flow findings (Golden et al., 1985; Kemali et al., 1985). It has been found to be a useful tool in predicting ventricular enlargement too. There are few studies from India regarding schizophrenia subtype specific cognitive profile on LNNB. 


\section{Cognitive Profile of Paranoid Schizophrenia on LNNB}

\section{METHODOLOGY:}

\section{Sample:}

Based on purposive sampling, 30 male hospitalized paranoid schizophrenia patients (as per ICD 10-DCR) from Ranchi Institute of Neuro- Psychiatry and Allied Sciences (RINPAS), Ranchi, India were selected for the study. Inclusion criteria required them to be literate, right- handed, and cooperative. Patients with other co-morbid psychiatric disorder, having history of organic pathology, substance abuse and mental retardation were excluded. Patients with vision and hearing impairment or significant physical illness too were excluded.

\section{Tools:}

- Socio Demographic and Clinical Data Sheet: A semi structured proforma designed for this study contained the socio-demographic and clinical data of the patients.

- Hand Preference questionnaire (Annett, 1970): Handedness of the patients was screened using the Hand Preference questionnaire. The questionnaire consists of 10 items indicating the preferred hand a person use for different tasks.

- Brief Psychiatric Rating Scale (BPRS), (Overall \& Gorham, 1962). BPRS is a reliable and widely used tool to assess psychopathology for severity and changes across treatment.

- The Luria Nebraska Neuropsychological Battery (LNNB-Form I). (Golden, et. al., 1985). The LNNB- I is a multidimensional battery designed to assess a broad range of neuropsychological functions. It consists of 269 items. Based on the basic functions involved, these items are arranged under eleven clinical scales, five summary scales, eight localization scales and twenty eight factor scales.

\section{Procedure:}

Patients were screened as per the inclusion and exclusion criteria and selected for the study. Clinical interview and required history was taken for the socio- demographic and clinical data sheet. Some information was collected and cross- checked from the case record file. Annett's Hand Preference questionnaire was used to decide handedness of the patients. BPRS was applied to screen out patients with severe psychopathology. LNNB- I was administered on the patients in two to three sessions. Obtained data were interpreted and appropriate descriptive statistics; mean, SD, and percentage were applied for the analysis of the data. 
RESULTS:

Table 1: Age and education of the patients

\begin{tabular}{|c|c|c|c|}
\hline Variable & Range & Mean & SD \\
\hline Age (in years) & $25-45$ & 31.63 & 6.51 \\
\hline Education (in years) & $9-15$ & 11.97 & 2.38 \\
\hline
\end{tabular}

Table 2: Clinical details of the patients

\begin{tabular}{|l|c|c|}
\hline \multicolumn{1}{|c|}{ Variable } & Range & Mean \\
\hline Age of onset (in years) & $19-36$ & 24.96 \\
\hline Duration of illness (in years) & $3-19$ & 6.5 \\
\hline & & \\
\hline BPRS score & No. & \% \\
\hline Very mild & 16 & 53.33 \\
\hline Mild & 14 & 46.67 \\
\hline
\end{tabular}

The age range of subjects was between $25-45$ years and the mean age was 31.63 years. Their education was between 9- 15 years (mean years of education was 11.97 years). Mean age of onset of illness was 24.96 years and average duration of illness was 6.5 years. All patients were having chronic illness. Findings of BPRS show that all patients were having either mild or very mild level of severity of psychopathology.

To prepare the mean profile for the paranoid schizophrenia patient, raw scores of all clinical and summary scales of LNNB-I were converted into T scores. Mean T scores and SD of all clinical and summary scales was calculated. Mean critical level was 57.

Table 3: Mean and SD of T scores of Clinical and Summary Scales of LNNB.

\begin{tabular}{|l|l|l|}
\hline Scales & \multicolumn{1}{|c|}{ Mean } & \multicolumn{1}{c|}{ SD } \\
\hline Motor Functions (C1) & 51.30 & 14.10 \\
\hline Rhythm (C2) & $\mathbf{6 7 . 4 7}$ & $\mathbf{1 6 . 7 7}$ \\
\hline Tactile Functions (C3) & 50.97 & 13.33 \\
\hline Visual Functions (C4) & $\mathbf{6 4 . 4 3}$ & $\mathbf{1 3 . 2 0}$ \\
\hline Receptive speech (C5) & $\mathbf{6 0 . 4 7}$ & $\mathbf{1 7 . 6 4}$ \\
\hline Expressive speech (C6) & 50.43 & 15.75 \\
\hline Writing (C7) & 52.40 & 11.32 \\
\hline Reading (C8) & 49.83 & 5.92 \\
\hline Arithmetic (C9) & $\mathbf{6 4 . 9 7}$ & $\mathbf{1 8 . 6 0}$ \\
\hline
\end{tabular}




\begin{tabular}{|l|l|l|}
\hline Memory (C10) & 57.87 & 14.93 \\
\hline Intellectual Processes (C11) & $\mathbf{6 8 . 8 0}$ & $\mathbf{1 5 . 6 0}$ \\
\hline Pathognomonic (S1) & 56.37 & 14.16 \\
\hline Left Hemisphere (S2) & 49.73 & 12.53 \\
\hline Right Hemisphere (S3) & 45.00 & 10.26 \\
\hline Profile Elevation (S4) & 68.60 & 20.43 \\
\hline Impairment (S5) & 63.30 & 12.63 \\
\hline
\end{tabular}

To assess the deficit in specific neuropsychological functions, item interpretation was done. Item interpretation shows that paranoid schizophrenia patients had high degree of impairment (more than $70 \%$ of the sample) in complex integrated operation, orientation and space, logical relation, contrast picture, Blurred picture, Application of grammatical structure, Sensory trace- tap and simple Integrated operation.

Table 4: LNNB items where more than $50 \%$ patients showed impairment

\begin{tabular}{|r|l|l|l|}
\hline $\begin{array}{l}\text { Sl. } \\
\text { no. }\end{array}$ & Item interpretation & $\begin{array}{l}\text { No. of patients } \\
\text { having } \\
\text { impairment }\end{array}$ & Percentage \\
\hline 1. & Selectivity of motor acts- speed & 15 & 50.00 \\
\hline 2. & Pitch perception & 16 & 53.33 \\
\hline 3. & Directionality & 15 & 50.00 \\
\hline 4. & Rhythm tap & 20 & 66.67 \\
\hline 5. & Blurred picture & $\mathbf{2 2}$ & $\mathbf{7 3 . 3 3}$ \\
\hline 6. & Contrast picture & $\mathbf{2 3}$ & $\mathbf{7 6 . 6 7}$ \\
\hline 7. & Visuo-spatial analysis & 19 & 63.33 \\
\hline 8. & Orientation and space & $\mathbf{2 5}$ & $\mathbf{8 3 . 3 3}$ \\
\hline 9. & Comprehension of grammatical structure & 16 & 53.33 \\
\hline 10 & Inverted grammatical structure & 15 & 50.00 \\
\hline 11 & Logical relation & $\mathbf{2 5}$ & $\mathbf{8 3 . 3 3}$ \\
\hline 12 & Application of grammatical structure & $\mathbf{2 2}$ & $\mathbf{7 3 . 3 3}$ \\
\hline 13 & Phonetic analysis & 19 & 63.33 \\
\hline 14 & Reading text & 15 & 50.00 \\
\hline 15 & Sensory trace- tap & $\mathbf{2 1}$ & $\mathbf{7 0 . 0 0}$ \\
\hline 16 & Logical memory & 18 & 60.00 \\
\hline
\end{tabular}




\begin{tabular}{|r|l|l|l|}
\hline 17 & Integrated operation- simple & $\mathbf{2 2}$ & $\mathbf{7 3 . 3 3}$ \\
\hline 18 & Integrated operation- complex & $\mathbf{2 0}$ & $\mathbf{8 6 . 6 7}$ \\
\hline
\end{tabular}

\section{DISCUSSION:}

The study was undertaken to identify cognitive impairment among paranoid schizophrenia patients using LNNB. The mean profile of paranoid schizophrenia in this study suggests impairment in the scales of Intellectual Process (C11), followed by Rhythm Scale (C2), Arithmetic (C9), Visual function (C4), and Receptive Speech (C5) on LNNB. The findings are consistent with Purisch et al. (1978) who identified four scales- C2, C10, C5, and C11 where schizophrenia patient showed impairment. Out of these four scales, findings of present study are similar for three scales (C2, C5, C11) where impairment was noticed. Findings are also consistent with Wells and Leventhal (1984). Different findings though have been reported by Langell et al. (1987) who found paranoid schizophrenia patients performing better than nonparanoid schizophrenia and non psychotic groups on Motor, Rhythm, Receptive Speech, Memory, and Intellectual Processes scales of the LNNB.

Talking specifically about memory, mean $\mathrm{T}$ score on memory scale (57.87) was slightly above the mean critical level (57). A substantial number of research studies examining memory have found paranoid schizophrenia participants to perform significantly better than non-paranoid participants. It could be suggested that under certain conditions, the paranoid subtype may demonstrate better memory functioning than the non-paranoid subtype. However, the complex interactions among assessment variables, including presentation (e.g., visual vs. auditory), stimuli (e.g., verbal vs. nonverbal), and interference (high vs. low), preclude any simple conclusions. Golden et al. (1980) and Paulman et al. (1990) on the contrary have found no subtype differences on this scale. Hamlin and Folsom (1977); Magaro and Page (1983) reported significant differences, with the paranoid subtype having better vocabulary performance in each case.

On item interpretation, impairment was seen highest in rhythm scale, where $73 \%$ patients showed impairment. These findings are also supported by Jain (1995). In evaluating the performance on the Rhythm (C2) scale, errors were found to occur on items assessing pitch perception, directionality, and rhythm tap. Along with the Rhythm Scale, highest number of patients had impairment in visual functions scale. Patients performed poorly in visuo- spatial analysis and orientation in space. Other studies also report schizophrenia patients performing poorly on visual spatial complex task (Yurgelun- Todd et al., 1993). In India, it was also reported that schizophrenia patients had impairment in visual functions (Nizamie, 1991), especially in visuo- spatial organization on LNNB scale. Item interpretation in Receptive Speech Scale indicated deficiency in the ability to analyze relational concepts and logical grammatical relationships. Patient's ability to understand the complex relationships between objects is 


\section{Cognitive Profile of Paranoid Schizophrenia on LNNB}

impaired. Inattention and poor memory skills offer explanation for his difficulties with these items. In the present study most of the patients showed impairment in sensory trace item, which indicates short term memory trace is not very stable for this group of patients. Poor performance in C11 scale is supported by Kelip et al., (1988); Sen \& Mazumder, (1983) where they found disturbance in abstraction and conceptual thinking. In the present study item interpretation indicates that significant number of the patients showed impairment in simple and complex integrated function. Overall findings of the present study are supported by present literature and re-establishes cognitive impairment in multiple domains in paranoid schizophrenia.

\section{REFERENCES:}

Andreasen, N. C., \& Olsen, S. (1982). Negative v positive schizophrenia. Definition and validation. Achieve of General Psychiatry. 39 (7), $789-794$.

Annett, M. (1970). A classification of hand preference by association analysis. British Journal of Psychology, 61, 303- 321.

Golden, C. J., Graber, B., Moses, J. A., \& Zatz, L. M. (1980). Differentiation of chronic schizophrenics with and without ventricular enlargement by the Luria- Nebraska Neuropsychological Battery. International Journal of Neuroscience, 11, 131 -138.

Golden, C.J., Purisch, A.D., Hammeke, T.A. (1985). Luria- Nebraska Neuropsychological Battery: Forms I \& II (Manual). Western Psychological Services, Los Angeles.

Hamlin, R.M, Folsom, A.T. (1977). Impairment in abstract responses of schizophrenics, neurotics, and brain-damaged patients. Journal of Abnormal Psychology. 5, 483-491.

Jain, A. (1995). Luria- Nebraska Neuropsychological Test Profile of manics, schizophrenics, and normal controls : A comparative study. M.Phil Dissertation, Ranchi University, Ranchi.

Kelip, J. G., Sweeney, J. A., Jacobson, P., Solomon, C., St Louis, L., Deck, M., France, A. \& Mann, J. J. (1988). Cognitive impairment in schizophrenia: specific relations to ventricular size and negative symptomatology. Biological Psychiatry, 24, 55 - 57.

Kemali, D., Maj, M., Golderisi, S., Ariano, M. C., Cesavelli, M., Milici, N., Salvati, A., Valente, A., \& Volpe, M. (1985). Clinical and neuropsychological correlates of cerebral ventricular enlargement in schizophrenia. Journal of Psychiatric Research, 19, 587 - 596.

Langell, M. E., Purisch, A. D. \& Golden, C. J. (1987). Neuropsychological differences between paranoid and non paranoid schizophrenics on the Luria- Nebraska Neuropsychological Battery. International Journal of Clinical Neuropsychology, 9, 88 -95.

Levin, S., Yurgelun- Todd, D. \& Craft, S (1989). Contribution of clinical neuropsychology to the study of schizophrenia. Journal of Abnormal Psychology, 98, $341-356$.

Magaro, P. A. (1981). The paranoid and the schizophrenic: The case for distinct cognitive style. Schizophrenia Bulletin, 7 (4), 632- 661.

Magaro, P. A., \& Page, J (1983). Brain disconnection, schizophrenia, and paranoia. Journal of Nervous \& Mental Disease. 171 (3), $133-140$. 


\section{Cognitive Profile of Paranoid Schizophrenia on LNNB}

Nizamie, A., Nizamie, S. H., \& Shukla, T. R. (1992). Performance on Luria- Nebraska Neuropsychological Battery in schizophrenic patients. Indian Journal of Psychiatry, 34, 321- 330.

Overall, J. E., \& Gorham, D. R. (1962). The Brief Psychiatric Rating Scale. Psychological Republication, 10: 799-812.

Paulman, R. G., Devous, M. D., Sr., Gregory, R. R., Herman, J. H., Jennings, L., Bonte, F. J., Nasrallah, H. A., \& Raese, J. D. (1990). Hypofrontality and cognitive impairment

Purisch, A.D., \& Sbordone, R. J. (1986). The Luria- Nebraska Neuropsychological Battery. In G. Goldstein \& R. A. Tarter (Eds.), Advances in Clinical Neuropsychology: Vol.3, 291- 316.

Robertson, G. \& Taylor, P. J. (1985). Some cognitive correlates of schizophrenic illnesses. Psychological Medicine. 15, 81 - 98.

Seidman, E. (1983). Unexamined premises of social problem-solving. In E. Seidman (Ed.), Handbook of Social Intervention. 48-67. Beverly Hills, CA: Sage.

Sen Mazumdar, D. P., \& Mazumdar, T.K. (1983). Abstract and concrete behavior of organic, schizophrenic, normal subjects on Goldstein Scheerer Cube Test. Indian Journal of Clinical Psychology, 10, 5- 10.

Wells DS, Leventhal D. Perceptual grouping in schizophrenia: Replication of Place and Gilmore. Journal of Abnormal Psychology. 1984, 93, 231-234.

World Health Organization (WHO) (1993). The ICD-10 Classification of Mental and Behavioural Disorders: Diagnostic Criteria for Research. WHO: Geneva.

Yurgelun-Todd, D.A., Kinney, D.K. (1993). Patterns of neuropsychological deficits discriminate schizophrenics from siblings and controls. Journal of Neuropsychiatry \& Clinical Neuroscience. 5, 294-300. 